\title{
Characterization of bronchiectasis in the elderly
}

\author{
Giuseppe Bellelli ${ }^{a}$, James D. Chalmers ${ }^{b}$, Giovanni Sotgiu ${ }^{c}$, Simone Dore ${ }^{c}$, \\ Melissa J. McDonnell ${ }^{d}$, Pieter C. Goeminne ${ }^{e}$, Katerina Dimakou ${ }^{f}$, Dusan Skrbic ${ }^{g}$, \\ Andrea Lombi ${ }^{\mathrm{h}}$, Federico Pane ${ }^{\mathrm{h}}$, Dusanka Obradovic ${ }^{\mathrm{g}}$, Thomas C. Fardon ${ }^{\mathrm{b}}$, \\ Robert M. Rutherford ${ }^{\mathrm{d}}$, Alberto Pesci ${ }^{\mathrm{h}}$, Stefano Aliberti ${ }^{\mathrm{i}, *}$

\footnotetext{
a School of Medicine and Surgery, University of Milan Bicocca, Geriatric Unit, ASST San Gerardo, Via Pergolesi 33, Monza, Italy

${ }^{\mathrm{b}}$ Tayside Respiratory Research Group, University of Dundee, Dundee, DD1 9SY, UK

${ }^{\mathrm{c}}$ Clinical Epidemiology and Medical Statistics Unit, Department of Biomedical Sciences, University of Sassarim, Research, Medical Education and Professional Development Unit, AOU Sassari, Sassari, Italy

d Department of Respiratory Medicine, Galway University Hospitals, Newcastle Road, Galway, H91YR71, Ireland

e University Hospital Gasthuisberg, Respiratory Medicine, Herestraat 49, B-3000 Leuven, Belgium

f 5th Pulmonary Department, "Sotiria" Chest Hospital, Athens, Greece

${ }^{g}$ Institute for Pulmonary Diseases of Vojvodina Sremska Kamenica, Clinic for General Pulmonology, Faculty of Medicine University of Novi Sad, Serbia

h School of Medicine and Surgery, University of Milan Bicocca, AO San Gerardo, Via Pergolesi 33, Monza, Italy

i Department of Pathophysiology and Transplantation, University of Milan, Cardio-thoracic Unit and Adult Cystic Fibrosis Center, Fondazione IRCCS Cà

Granda Ospedale Maggiore Policlinico, Milan, Italy
}

\section{A R T I C L E I N F O}

\section{Article history:}

Received 25 March 2016

Received in revised form

8 July 2016

Accepted 15 August 2016

Available online 17 August 2016

\section{Keywords:}

Frailty

Cystic fibrosis

Pseudomonas

COPD

Comorbidity

\begin{abstract}
A B S T R A C T
Introduction: Although bronchiectasis particularly affects people $\geq 65$ years of age, data describing clinical characteristics of the disease in this population are lacking. This study aimed at evaluating bronchiectasis features in older adults and elderly, along with their clinical outcomes.

Methods: This was a secondary analysis of six European databases of prospectively enrolled adult outpatients with bronchiectasis. Bronchiectasis characteristics were compared across three study groups: younger adults ( $18-65$ years), older adults (66-75 years), and elderly (and $\geq 76$ years). 3-year mortality was the primary study outcome.

Results: Among 1258 patients enrolled (median age: 66 years; $42.5 \%$ males), 50.9\% were $\geq 65$ years and $19.1 \geq 75$ years old. Elderly patients were more comorbid, had worse quality of life and died more frequently than the others. Differences were detected among the three study groups with regard to neither the etiology nor the severity of bronchiectasis, nor the prevalence of chronic infection with P. aeruginosa. In multivariate regression model, age (OR: 1.05; p-value: <0.0001), low BMI (OR: 2.63; pvalue: 0.02 ), previous hospitalizations (OR: 2.06; p-value: 0.006 ), and decreasing $\mathrm{FEV}_{1}$ (OR: 1.02 ; p-value: 0.001 ) were independent predictors of 3-year mortality, after adjustment for covariates.

Conclusion: Bronchiectasis does not substantially differ across age groups. Poor outcomes in elderly patients with bronchiectasis might be directly related to individual's frailty that should be further investigated in clinical studies.
\end{abstract}

() 2016 Elsevier Ltd. All rights reserved.

Abbreviation: ABPA, Allergic Broncho-Pulmonary Aspergillosis; BMI, body mass index; BSI, Bronchiectasis Severity Index; BTS, British Thoracic Society; CCI, Charlson

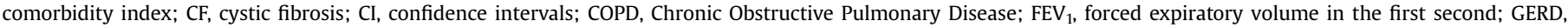

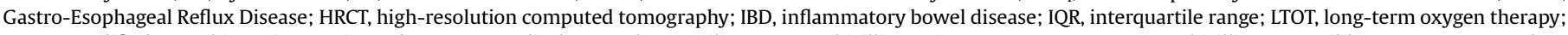

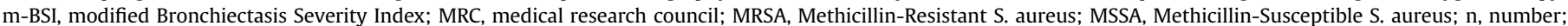
OR, odds ratios; SD, standard deviation; SGRQ, St. George's Respiratory Questionnaire.

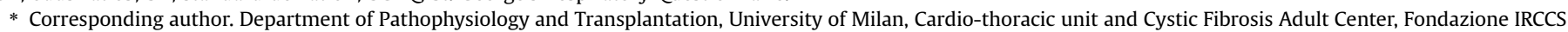
Cà Granda Ospedale Maggiore Policlinico, Via Francesco Sforza 35, 20122, Milan, Italy.

E-mail address: stefano.aliberti@unimi.it (S. Aliberti). 


\section{Introduction}

Bronchiectasis is a chronic airway disease characterized by irreversibly damaged and dilated bronchi leading to recurrent episodes of respiratory infection [1]. Data from both United States of America (USA) and Europe have suggested that the clinical importance of bronchiectasis is rising reflecting an increase in prevalence, hospital admissions and mortality $[2,3]$.

Much of our knowledge on the management and treatment of bronchiectasis is based on cystic fibrosis (CF), mainly recognized as a disease of children and young adults. In contrast, analyses from administrative databases highlighted that bronchiectasis predominantly affects elderly people increasing mortality of approximately $3 \%$ per year and causing a high economic burden on healthcare systems $[3,4]$.

Management of many diseases in the elderly is more complex than in younger patients due to the impact of several age-related conditions, including comorbidities, cognitive impairment, and frailty, all of which can independently affect adherence to polypharmacological regimens, follow-up visits, hospitalizations, and the patient's overall survival [5]. Despite the recognition that bronchiectasis seems to occur most commonly in the elderly, there are no large-scale studies characterizing the extent to which age impacts clinical features and outcomes of this disease.

The aim of this study was to evaluate clinical, radiological, microbiological, and functional characteristics, along with the severity of the disease and clinical outcomes, in adults and elderly patients with bronchiectasis.

\section{Materials and methods}

\subsection{Study population}

This study is part of the FRIENDS (Facilitating Research Into Existing National DataSet) project aimed to foster collaboration within the EMBARC network [6]. It was a secondary analysis of six databases of prospectively enrolled outpatients with bronchiectasis referred to the bronchiectasis clinics of university teaching hospitals in Monza (Italy), Dundee (UK), Leuven (Belgium), Athens (Greece), Sremska Kamenica (Serbia) and Galway (Ireland) between 2009 and 2014. Consecutive patients aged $\geq 18$ years with a diagnosis of bronchiectasis on high-resolution computed tomography (HRCT) scan in stable state were enrolled. Patients with cystic fibrosis or traction bronchiectasis due to pulmonary fibrosis were excluded. A further exclusion criterion for the Leuven cohort was the presence of active cancer. Collection of selected variables was approved at each individual center by the local ethical committee or institutional review board.

\subsection{Data collection}

At the time of baseline assessment, all patients were clinically stable and underwent the same comprehensive diagnostic work-up in each site according to the 2010 British Thoracic Society (BTS) guidelines [7]. Demographics, comorbidity, severity of the disease, etiology of bronchiectasis, respiratory symptoms, sputum evaluation, radiological, functional, and laboratory findings during clinical stability, quality of life and outcomes during a three-year follow-up period were uniformly recorded in each local database. Process to define the etiology of bronchiectasis is reported in the supplementary material.

The Charlson comorbidity index (CCI) was used to assess comorbidity; this is a sum score of 19 weighted diseases with higher scores denoting increasing burden of comorbidity [8]. COPD was defined according to the GOLD initiative [9]. The severity of bronchiectasis was evaluated according to the Bronchiectasis Severity Index (BSI) [10]. In addition, in some analyses comparing different age groups, a modified BSI (m-BSI), calculated without including age as a factor, was used. Radiological severity of bronchiectasis was assessed using a modified Reiff score, which rates the number of involved lobes (with the lingula considered to be a separate lobe) and the degree of dilatation (range: 1-18) [10]. Each participating center performed standardized etiological testing recommended by the BTS guidelines [7]. St. George's Respiratory Questionnaire was administered to measure patients' quality of life [11]. Chronic infection was defined by the isolation of potentially pathogenic bacteria in sputum culture on two or more occasions, at least 3 months apart over a 1-year period [12]. The predominant pathogen was the organism grown most frequently over the study period. Patients who were unable to provide sputum samples due to absence of a productive cough were classified as not having a chronic infection for the purposes of analysis as previously described.

\subsection{Study groups and outcomes}

The cohort was split into three groups based on age at enrolment: 18-65 years (younger adults), 66-75 years (older adults), and 76 years or over (elderly). The primary outcome was all-cause mortality at three-year follow-up. Exacerbations and hospitalizations were secondary outcomes (see supplementary material).

\subsection{Statistical analysis}

All statistical analyses were run using Stata ${ }^{\circledR} 13$ (StataCorp, College Station, TX, USA). Categorical data are presented as absolute number (n) and percentage (\%). Normally distributed data are shown as mean with standard deviation (SD), whereas nonnormally distributed data are presented as median with interquartile range (IQR). The chi-squared test and Mann Whitney U test were used for comparison of categorical and non-parametric numerical data, respectively. For comparisons of more than two groups, one-way analysis of variance or the Kruskal-Wallis test were used as appropriate. The association between 3-year mortality and collected variables was evaluated using uni- and multivariate logistic regressions reporting odds ratios (OR) and 95\% confidence intervals [CI]. Age and m-BSI scores were divided in tertiles, while CCI score was dichotomized (i.e., $\leq 1$ vs. $\geq 2$ ), according to their distribution. The covariates were chosen with $a$ priori-selection based on previous research and clinical rationale (i.e., independent association with mortality in elderly patients with respiratory diseases). The calculated p-values were two-tailed, with values less than 0.05 considered statistically significant.

\section{Results}

\subsection{Study sample}

A total of 1258 patients were enrolled within the six centers (median [IQR] age: 66 [56-74] years; $42.5 \%$ males): 286 patients in Dundee, 280 in Galway, 230 in Monza, 190 in Leuven, 159 in Athens, and 113 in Sremska Kamenica, see Table A (supplementary material). Distribution of patients according to age is depicted in Fig. 1 with a range from 18 to 94 years. Among the entire study sample, 618 patients (49\%) were younger adults, 400 (32\%) older adults, and 240 (19\%) were elderly. Among this last group, 34 patients $(2.7 \%)$ patients were 85 years of age or older.

Demographics, clinical, functional and radiological status, microbiology, severity of the disease, quality of life, and long-term treatment of the three age groups are presented in Table 1. A 


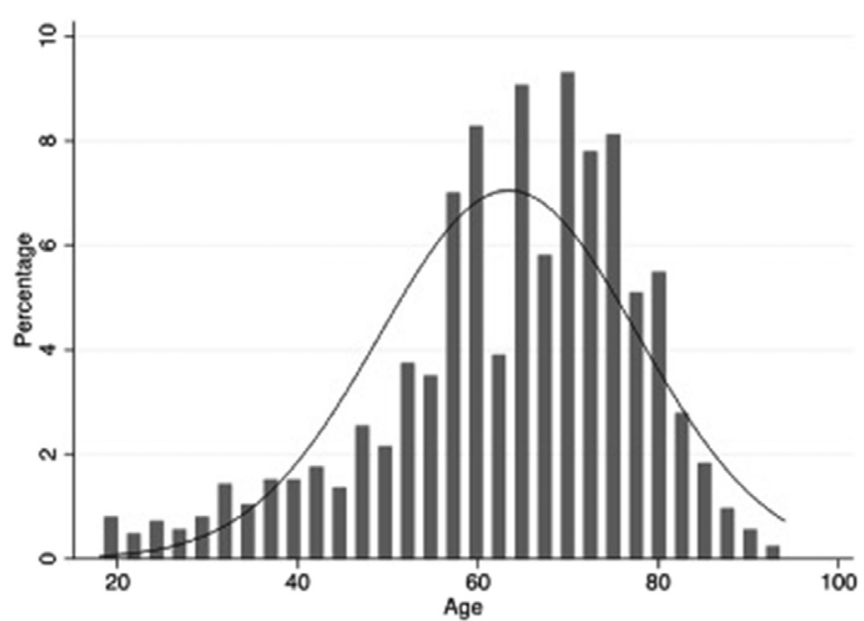

Fig. 1. Distribution of patients according to age.

significantly higher prevalence of males and smoker/ex-smokers, a worse radiological impairment and pulmonary function status, higher comorbidity prevalence, and a worse quality of life were detected in older adults and elderly patients in comparison to younger adults. The global severity of bronchiectasis evaluated with the m-BSI was not different among the age groups. Younger adults, older adults, and elderly patients showed no significant differences in terms of clinical symptoms related to bronchiectasis, including daily cough, daily sputum and haemoptysis, nor systemic inflammation during stable state.

The most common etiologies of bronchiectasis were postinfective (25\%), COPD-related (13\%), connective tissue diseaserelated $(7.1 \%)$, and immunodeficiency (4.5\%), while bronchiectasis was idiopathic in $36 \%$ of the patients. While bronchiectasis related to asthma, inflammatory bowel disease (IBD), and ciliary dysfunction were more prevalent in younger adults, COPD-related bronchiectasis was more prevalent in older adults and elderly patients, see Table 2. No other significant differences in terms of prevalence of the etiologies were detected when the three study groups were compared.

\subsection{Microbiology}

Microbiology and long-term antibiotic therapy are reported in Table 3. No significant differences among age groups were detected with regard to chronic infection with Pseudomonas aeruginosa. The only significant differences in terms of prevalence of chronic infection among the different age groups were detected for

Table 1

Demographic, clinical and epidemiological patients' characteristics stratified according to age.

\begin{tabular}{|c|c|c|c|c|c|}
\hline Variable & Indicator & $\begin{array}{l}\text { 18-65 years (Younger adults) } \\
(\mathrm{n}=618)\end{array}$ & $\begin{array}{l}\text { 66-75 years (Older adults) } \\
(\mathrm{n}=400)\end{array}$ & $\begin{array}{l}\geq 76 \text { years (Elderly) } \\
(\mathrm{n}=240)\end{array}$ & p-value \\
\hline \multicolumn{6}{|l|}{ Demographics } \\
\hline Age, years & median (IQR) & $56(46-61)$ & $71(68-73)$ & $80(78-82)$ & $0.0001^{\mathrm{a}, \mathrm{b}, \mathrm{c}}$ \\
\hline Male & $\mathrm{n}(\%)$ & $232(38)$ & $174(44)$ & $129(54)$ & $<0.0001^{\mathrm{b}, \mathrm{c}}$ \\
\hline Underweight & $\mathrm{n}(\%)$ & $43(7.3)$ & $27(7)$ & $15(6.6)$ & 0.94 \\
\hline Either smokers or ex-smokers & $\mathrm{n}(\%)$ & $233(38)$ & $169(42)$ & $116(48)$ & $0.015^{\mathrm{b}}$ \\
\hline \multicolumn{6}{|l|}{ Severity of the disease } \\
\hline BSI score & median (IQR) & $4(3-9)$ & $7(5-11)$ & $9(7-13)$ & $0.0001^{\mathrm{a}, \mathrm{b}, \mathrm{c}}$ \\
\hline Modified BSI & median (IQR) & $3(1-7)$ & $3(1-8)$ & $4(2-8)$ & 0.072 \\
\hline \multicolumn{6}{|l|}{ Radiological Status } \\
\hline Reiff score & Mean (SD) & $4.2(2.9)$ & $4.9(3.3)$ & $5.1(3.1)$ & $<0.001^{\mathrm{a}, \mathrm{b}}$ \\
\hline \multicolumn{6}{|l|}{ Comorbidity } \\
\hline Charlson Comorbidity Index $>1$ & $\mathrm{n}(\%)$ & $154(25)$ & $159(40)$ & $126(53)$ & $<0.0001^{\mathrm{a}, \mathrm{b}}$ \\
\hline COPD & $\mathrm{n}(\%)$ & $86(14)$ & $86(22)$ & $77(32)$ & $<0.0001^{\mathrm{c}}$ \\
\hline Diabetes mellitus & $\mathrm{n}(\%)$ & $47(7.6)$ & $56(14)$ & $31(13)$ & $0.002^{\mathrm{a}}$ \\
\hline Chronic renal failure & $\mathrm{n}(\%)$ & $30(4.9)$ & $23(5.8)$ & $34(14)$ & $<0.0001^{\mathrm{b}, \mathrm{c}}$ \\
\hline Chronic heart failure & $\mathrm{n}(\%)$ & $49(7.9)$ & $57(14)$ & $40(17)$ & $<0.0001^{\mathrm{a}, \mathrm{b}}$ \\
\hline Previous acute myocardial infarction & $\mathrm{n}(\%)$ & $34(5.5)$ & $49(12)$ & 45 (19) & $<0.0001^{\mathrm{a}, \mathrm{b}}$ \\
\hline Mild liver disease & $\mathrm{n}(\%)$ & $9(1.5)$ & $6(1.5)$ & $3(1.3)$ & 0.97 \\
\hline Moderate-to-severe liver disease & $\mathrm{n}(\%)$ & $7(1.1)$ & $6(1.5)$ & $3(1.3)$ & 0.88 \\
\hline Previous cerebro-vascular accident & $\mathrm{n}(\%)$ & $20(3.2)$ & $23(5.8)$ & $22(9.2)$ & $0.002^{\mathrm{b}}$ \\
\hline Peripheral vascular disease & $\mathrm{n}(\%)$ & $37(6.0)$ & $26(6.5)$ & $43(18)$ & $<0.0001^{\mathrm{b}, \mathrm{c}}$ \\
\hline Dementia & n.(\%) & $1(0.2)$ & $5(1.3)$ & $8(3.3)$ & $<0.0001^{\mathrm{b}}$ \\
\hline Rheumatologic disease & $\mathrm{n}(\%)$ & $50(8.1)$ & $49(12)$ & $21(8.8)$ & 0.08 \\
\hline Peptic ulcer disease & $\mathrm{n}(\%)$ & $28(4.5)$ & $31(7.8)$ & $20(8.3)$ & $0.04^{\mathrm{a}, \mathrm{b}}$ \\
\hline Solid tumor & $\mathrm{n}(\%)$ & $27(4.4)$ & $48(12)$ & $25(10)$ & $<0.0001^{\mathrm{a}, \mathrm{b}}$ \\
\hline Leukemia & $\mathrm{n}(\%)$ & $4(0.7)$ & $9(2.3)$ & $1(0.4)$ & $0.03^{\mathrm{a}}$ \\
\hline Lymphoma & $\mathrm{n}(\%)$ & $1(0.2)$ & $3(0.8)$ & $3(1.3)$ & 0.13 \\
\hline HIV infection & $\mathrm{n}(\%)$ & $2(0.3)$ & $0(0)$ & $0(0)$ & 0.69 \\
\hline \multicolumn{6}{|c|}{ Clinical, laboratory and functional status } \\
\hline Daily cough & $\mathrm{n}(\%)$ & $457(74)$ & $291(73)$ & $175(73)$ & 0.90 \\
\hline Daily sputum & $\mathrm{n}(\%)$ & $357(58)$ & $255(64)$ & $144(60)$ & 0.16 \\
\hline Prior history of haemoptysis & $\mathrm{n}(\%)$ & $102(17)$ & $77(19)$ & $39(16)$ & 0.47 \\
\hline MRC class IV and V & $\mathrm{n}(\%)$ & $91(17)$ & $94(26)$ & $62(27)$ & $<0.0001^{\mathrm{a}, \mathrm{b}}$ \\
\hline LTOT & $\mathrm{n}(\%)$ & $39(6.3)$ & $39(9.8)$ & $20(8.3)$ & 0.13 \\
\hline $\mathrm{FEV}_{1}, \%$ predicted & median (IQR) & $78(57-96)$ & $75(53-94)$ & $67(51-84)$ & $0.0002^{\mathrm{b}, \mathrm{c}}$ \\
\hline C-reactive protein, $\mathrm{mg} / \mathrm{L}$ & median (IQR) & $5(2-9)$ & $5(3-10)$ & $6(3-12)$ & 0.10 \\
\hline \multicolumn{6}{|l|}{ Quality of life } \\
\hline SGRQ & median (IQR) & $36.1(24.5-51.5)$ & $38.9(26.4-59.6)$ & $50.8(32.3-63.3)$ & $0.007^{\mathrm{b}}$ \\
\hline
\end{tabular}

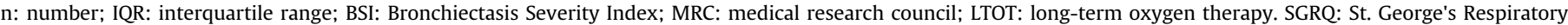

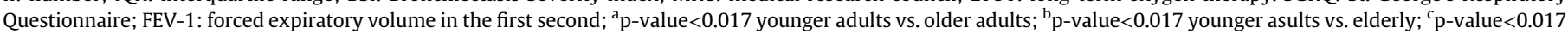
older adults vs. elderly. 
Table 2

Etiology of bronchiectasis in the three study groups.

\begin{tabular}{|c|c|c|c|c|c|}
\hline Disease & Indicator & $\begin{array}{l}\text { 18-65 years (Younger adults) } \\
(\mathrm{n}=618)\end{array}$ & $\begin{array}{l}\text { 66-75 years (Older adults) } \\
(\mathrm{n}=400)\end{array}$ & $\begin{array}{l}\geq 76 \text { years (Elderly) } \\
(\mathrm{n}=240)\end{array}$ & p-value \\
\hline Idiopathic & $\mathrm{n}(\%)$ & $211(34)$ & $156(39)$ & $88(37)$ & 0.29 \\
\hline Post-infective & $\mathrm{n}(\%)$ & $154(25)$ & $104(26)$ & $51(21)$ & 0.39 \\
\hline COPD & $\mathrm{n}(\%)$ & $50(8.1)$ & $51(13)$ & $57(24)$ & $<0.0001^{\mathrm{a}, \mathrm{b}, \mathrm{c}}$ \\
\hline Connective tissue disease & $\mathrm{n}(\%)$ & $41(6.6)$ & $32(8.0)$ & $16(6.7)$ & 0.68 \\
\hline Immunodeficiency & $\mathrm{n}(\%)$ & $31(5.0)$ & $18(4.5)$ & $8(3.3)$ & 0.57 \\
\hline ABPA & $\mathrm{n}(\%)$ & $30(4.9)$ & $15(3.8)$ & $9(3.8)$ & 0.63 \\
\hline Asthma & $\mathrm{n}(\%)$ & $29(4.7)$ & $8(2.0)$ & $4(1.7)$ & $0.02^{\mathrm{a}, \mathrm{b}}$ \\
\hline Inflammatory bowel disease & $\mathrm{n}(\%)$ & $18(2.9)$ & $4(1.0)$ & $2(0.8)$ & 0.04 \\
\hline Ciliary dysfunction & $\mathrm{n}(\%)$ & $19(3.1)$ & $1(0.3)$ & $0(0)$ & $<0.0001^{\mathrm{a}, \mathrm{b}}$ \\
\hline Aspiration/GERD & $\mathrm{n}(\%)$ & $7(1.1)$ & $4(1.0)$ & $3(1.3)$ & 0.96 \\
\hline Alpha- 1 antitrypsin deficiency & $\mathrm{n}(\%)$ & $10(1.6)$ & $2(0.5)$ & $0(0)$ & 0.06 \\
\hline Congenital & $\mathrm{n}(\%)$ & $5(0.8)$ & $0(0)$ & $0(0)$ & 0.07 \\
\hline Obstructive (lung carcinoid) & $\mathrm{n}(\%)$ & $1(0.2)$ & $0(0)$ & $0(0)$ & 0.60 \\
\hline Other & $\mathrm{n}(\%)$ & $11(1.8)$ & $5(1.3)$ & $3(1.3)$ & 0.83 \\
\hline
\end{tabular}

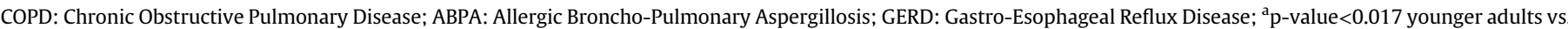
older adults; ${ }^{\mathrm{b}} \mathrm{p}$-value $<0.017$ younger asults vs. elderly; ${ }^{\mathrm{c}} \mathrm{p}$-value $<0.017$ older adults vs. elderly.

Table 3

Microbiology and long-term antibiotic treatment in the entire study population and in different sub-groups.

\begin{tabular}{|c|c|c|c|c|c|}
\hline Variables & Indicator & $\begin{array}{l}\text { 18-65 years (Younger adults) } \\
(\mathrm{n}=618)\end{array}$ & $\begin{array}{l}\text { 66-75 years (Older adults) } \\
(\mathrm{n}=400)\end{array}$ & $\begin{array}{l}\geq 76 \text { years (Elderly) } \\
(\mathrm{n}=240)\end{array}$ & p-value \\
\hline $\begin{array}{l}\text { Patients with chronic infection } \\
\text { Chronic infection with }\end{array}$ & $\mathrm{n}(\%)$ & $229(37)$ & $147(37)$ & $80(33)$ & 0.58 \\
\hline P. aeruginosa & $\mathrm{n}(\%)$ & $83(13)$ & $62(16)$ & $36(15)$ & 0.63 \\
\hline H. influenzae & $\mathrm{n}(\%)$ & $113(18)$ & $51(13)$ & $21(8.8)$ & $0.001^{\mathrm{b}}$ \\
\hline S. aureus & $\mathrm{n}(\%)$ & $43(7)$ & $25(6.3)$ & $14(5.8)$ & 0.81 \\
\hline MRSA & $\mathrm{n}(\%)$ & $10(1.6)$ & $7(1.8)$ & $4(1.7)$ & 1.00 \\
\hline MSSA & $\mathrm{n}(\%)$ & $33(5.3)$ & $18(4.5)$ & $10(4.2)$ & 0.72 \\
\hline S. pneumoniae & $\mathrm{n}(\%)$ & $33(5.3)$ & $11(2.8)$ & $3(1.3)$ & $0.007^{\mathrm{b}}$ \\
\hline M. catarrhalis & $\mathrm{n}(\%)$ & $30(4.9)$ & $13(3.3)$ & $7(2.9)$ & 0.29 \\
\hline Enterobacteriaceae & $\mathrm{n}(\%)$ & $19(3.1)$ & $24(6.0)$ & $19(7.9)$ & $0.006^{\mathrm{b}}$ \\
\hline K. pneumoniae & $\mathrm{n}(\%)$ & $6(1.0)$ & $3(0.8)$ & $4(1.7)$ & 0.54 \\
\hline E. coli & $\mathrm{n}(\%)$ & $4(0.7)$ & $6(1.5)$ & $4(1.7)$ & 0.23 \\
\hline Proteus spp. & $\mathrm{n}(\%)$ & $1(0.2)$ & $3(0.8)$ & $1(0.4)$ & 0.34 \\
\hline A. fumigatus & $\mathrm{n}(\%)$ & $2(0.3)$ & $1(0.3)$ & $1(0.4)$ & 1.00 \\
\hline Others & $\mathrm{n}(\%)$ & $6(1)$ & $16(4)$ & $6(2.5)$ & $0.01^{\mathrm{a}}$ \\
\hline
\end{tabular}

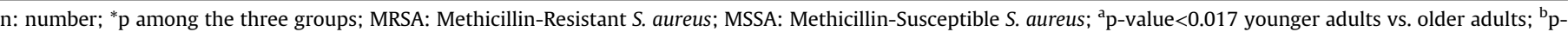
value $<0.017$ younger asults vs. elderly; ${ }^{c} \mathrm{p}$-value $<0.017$ older adults vs. elderly.

Haemophilus influenzae (more prevalent in younger adults), Streptococcus pneumoniae (more prevalent in younger adults), and Enterobacteriaceae (more prevalent in older adults and elderly patients).

\subsection{Study outcomes}

Data on outcomes were not available for 37 patients at 1-year and for 219 patients at 2 and 3-year follow up. Among the entire sample, during the first year of follow up the median (IQR) number of exacerbations was $1(0-2)$, and 221 patients (19\%) experienced at least one severe exacerbation requiring hospitalization. Mortality was $3.4 \%$ at one year, $6.6 \%$ at two years, and $11 \%$ at three years. Prevalence of study outcomes in the three age groups is shown in Table 4.

The logistic regression analysis, adjusted for several confounders including centers, highlighted the role of age (OR: 1.05; pvalue: <0.0001), low BMI (OR: 2.63; p-value: 0.02), previous hospitalizations (OR: 2.06; p-value: 0.006), and decreasing $\mathrm{FEV}_{1}(\mathrm{OR}$ : 1.02; p-value: 0.001 ) as independent predictors of 3-year mortality in the entire cohort (Table 5).

Table 4

Follow-up data among the three study groups.

\begin{tabular}{|c|c|c|c|c|c|}
\hline Variables & Indicator & $\begin{array}{l}\text { 18-65 years (Younger adults) } \\
(\mathrm{n}=618)\end{array}$ & $\begin{array}{l}\text { 66-75 years (Older adults) } \\
(\mathrm{n}=400)\end{array}$ & $\begin{array}{l}\geq 76 \text { years (Elderly) } \\
(\mathrm{n}=240)\end{array}$ & p-value \\
\hline$\geq 2$ exacerbations in 1 -year follow up & n.(\%) & $266(43)$ & $170(43)$ & $96(40)$ & 0.70 \\
\hline$\geq 3$ exacerbations in 1 -year follow up & n.(\%) & $105(18)$ & $78(21)$ & $39(17)$ & 0.39 \\
\hline$\geq 1$ hospitalization in 1 -year follow up & n.(\%) & $100(17)$ & $62(17)$ & $59(26)$ & $0.005^{\mathrm{b}, \mathrm{c}}$ \\
\hline Mortality in 1-year follow up & n.(\%) & $12(2.0)$ & $12(3.1)$ & $18(7.9)$ & $<0.0001^{\mathrm{b}, \mathrm{c}}$ \\
\hline Mortality in 2-year follow up & n.(\%) & $21(3.9)$ & $23(7.5)$ & $25(13)$ & $<0.0001^{\mathrm{a}, \mathrm{b}}$ \\
\hline Mortality in 3-year follow up & n.(\%) & $31(5.8)$ & $39(13)$ & $41(21)$ & $<0.0001^{\mathrm{a}, \mathrm{b}, \mathrm{c}}$ \\
\hline
\end{tabular}

${ }^{a}$ p-value $<0.017$ younger adults vs. older adults; ${ }^{b}$ p-value $<0.017$ younger asults vs. elderly; ${ }^{c}$-value $<0.017$ older adults vs. elderly. 
Table 5

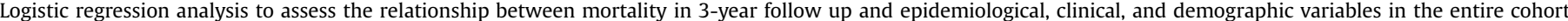
$(\mathrm{N}=1039)$.

\begin{tabular}{|c|c|c|c|c|}
\hline \multicolumn{5}{|l|}{ Mortality in 3-year follow up (entire cohort) } \\
\hline \multirow[t]{2}{*}{ Variables } & \multicolumn{2}{|l|}{ Univariate } & \multicolumn{2}{|l|}{ Multivariate } \\
\hline & Odds ratio (IC 95\%) & p-value & Odds ratio (IC 95\%) & p-value \\
\hline Age, years & $1.06(1.04-1.08)$ & $<0.0001$ & $1.05(1.03-1.08)$ & $<0.0001$ \\
\hline Male & $2.69(1.78-4.05)$ & $<0.0001$ & $1.53(0.92-2.54)$ & 0.10 \\
\hline Underweight & $3.19(1.71-5.95)$ & $<0.0001$ & $2.63(1.20-5.75)$ & 0.02 \\
\hline Smokers/Ex-smokers & $2.85(1.89-4.28)$ & $<0.0001$ & $1.22(0.69-2.17)$ & 0.50 \\
\hline Reiff score & $2.35(1.50-3.68)$ & $<0.0001$ & $0.98(0.57-1.69)$ & 0.95 \\
\hline Daily cough & $0.85(0.54-1.33)$ & 0.47 & & \\
\hline Daily sputum & $0.80(0.54-1.19)$ & 0.27 & & \\
\hline Prior history of haemoptysis & $0.83(0.47-1.47)$ & 0.52 & & \\
\hline MRC class IV and V & $3.71(2.46-5.60)$ & $<0.0001$ & $1.39(0.82-2.35)$ & 0.23 \\
\hline Exacerbations in the previous year & $1.10(1.00-1.22)$ & 0.06 & & \\
\hline$\geq 1$ hospitalization in the previous year & $2.69(1.80-4.01)$ & $<0.0001$ & $2.06(1.23-3.46)$ & 0.006 \\
\hline Decreasing $\mathrm{FEV}_{1}, \%$ predicted & $1.04(1.03-1.05)$ & $<0.0001$ & $1.02(1.01-1.03)$ & 0.001 \\
\hline Individuals with a bacterial colonization & $1.05(0.70-1.57)$ & 0.81 & & \\
\hline P. aeruginosa infection & $1.84(1.14-2.96)$ & 0.012 & $1.33(0.71-2.50)$ & 0.37 \\
\hline Individuals with $\geq 2$ bacterial colonizations & $0.98(0.55-1.74)$ & 0.94 & & \\
\hline Bacterial infection than $P$. aeruginosa infection & $0.62(0.37-1.03)$ & 0.07 & & \\
\hline Previous cerebro-vascular accident & $1.67(0.82-3.38)$ & 0.16 & & \\
\hline Dementia & $6.21(1.94-19.90)$ & 0.002 & $1.80(0.48-6.69)$ & 0.38 \\
\hline COPD & $4.23(2.80-6.41)$ & $<0.0001$ & $1.52(0.81-2.83)$ & 0.19 \\
\hline Rheumatologic disease & $1.51(0.84-2.72)$ & 0.17 & & \\
\hline Hematological malignancy & $1.40(0.41-4.85)$ & 0.59 & & \\
\hline Moderate-to-severe liver disease & $1.26(0.37-4.31)$ & 0.71 & & \\
\hline Diabetes mellitus-related organ damage & $0.48(0.11-2.04)$ & 0.32 & & \\
\hline Leukemia & $1.53(0.33-6.99)$ & 0.58 & & \\
\hline Lymphoma & $1.40(0.17-11.71)$ & 0.76 & & \\
\hline ABPA & $0.52(0.16-1.70)$ & 0.28 & & \\
\hline Aspiration/GERD & $1.40(0.31-6.34)$ & 0.66 & & \\
\hline Asthma & $0.75(0.23-2.50)$ & 0.64 & & \\
\hline Connective tissue disease & $1.27(0.65-2.47)$ & 0.48 & & \\
\hline Inflammatory bowel disease & $1.20(0.27-5.34)$ & 0.81 & & \\
\hline Immunodeficiency & $0.95(0.37-2.44)$ & 0.91 & & \\
\hline Post-infective etiology & $0.74(0.45-1.20)$ & 0.22 & & \\
\hline Long-term macrolide and/or inhaled antibiotic treatment & $1.13(0.75-1.69)$ & 0.55 & & \\
\hline Long-term macrolide treatment & $0.95(0.63-1.45)$ & 0.82 & & \\
\hline
\end{tabular}

MRC: medical research council; $\mathrm{FEV}_{1}$ : forced expiratory volume in the first second; COPD: Chronic Obstructive Pulmonary Disease; BMI: body mass index.

\section{Discussion}

Our study shows that among bronchiectasis patients referring to six European tertiary care centers, more than $50 \%$ are over 65 years with almost one out of five greater than 75 years of age. Predictably, oldest patients have an increased comorbidity level, experience a worse quality of life and die more frequently during a 3-year follow-up in comparison to younger adults. However, bronchiectasis severity, signs and symptoms of the disease, systemic inflammation and chronic infection with $P$. aeruginosa did not different among older adults, elderly and younger adults.

Little information is available across Europe regarding the prevalence of bronchiectasis in older people. According to data provided by the German Federal Insurance Authority, individuals aged 75 years or more have the highest prevalence of bronchiectasis, up to 228 and 200 per 100,000 population in men and women, respectively [13]. By confirming high bronchiectasis prevalence in older adults and elderly people, our data represent a significant step forward in this field since we collated data from multicenter, observational cohorts of consecutively enrolled patients from several countries. We decided to identify three age groups because elderly represents a very heterogeneous group of patients. According to several studies, the cut-off of 65 years is not representative of the biological complexity of the whole elderly population. Therefore, we decided to stratify people over 65 years of age into two more groups in order to appreciate several differences in clinical characteristics and outcomes.
Western countries are experiencing an "ageing population" with older people representing the fastest growing section of the whole population; hence, it is imperative to try to understand the mechanisms regulating the interaction among different diseases in these individuals. The high comorbidity burden that characterizes our cohort represents the substrate for an increased risk of disability and frailty in older subjects [14]. Furthermore, it represents the clinical background for a frequent use of health care services and for a worse quality of life for elderly patients $[15,16]$.

We found that age is an independent predictor of 3-year mortality, in line with previously published literature [10]. Increasing age was associated with an increased mortality risk (hazard ratio: 1.045 ) in a prospective study carried out in Belgium and in a cohort study in the UK (relative risk: 1.10 ) [17,18]. The role of age may be explained with an increased risk of reduced biological reserve occurring with age and comorbidity. Indeed, age is an important risk factor for frailty [19]. Frailty represents a state of increased vulnerability related to a poor level of homeostasis after a stressful event, with a corresponding increased risk of adverse outcomes [19]. Several studies showed that frailty is a much more powerful predictor of poor outcomes than age, indirectly suggesting that if frailty is taken into account in the pathophysiological relationship with mortality, age could weaken its importance [20-22]. Future studies in older people with bronchiectasis should, therefore, consider frailty as a crucial factor and record variables such as weakness, low gait speed, poor endurance, and cognitive impairment. 
At least three important findings of the present study may contribute to expand our knowledge on bronchiectasis. First, no significant differences seem to exist in etiologies of bronchiectasis among younger adults, older adults and elderly, except for COPDassociated bronchiectasis, which was most common in the elderly, and bronchiectasis associated to ciliary dysfunctions, asthma or IBD, which was most common among younger adults. Second, we found that variables specifically related to bronchiectasis showed similar frequencies across all age groups. In particular, signs and symptoms of bronchiectasis, the level of systemic inflammation, and exacerbation rates during follow-up did not significantly vary among the three age groups. Third, we identified similar prevalence of pathogens leading to chronic infections among the selected age groups, with the only exceptions of S. pneumoniae and $H$. influenzae which were most prevalent among the younger adults and Enterobacteriaceae which was most prevalent in the elderly group.

Notably, prevalence of chronic infection with $P$. aeruginosa was not different by age. The presence of $P$. aeruginosa in bronchiectasis patients clearly defines a specific clinical phenotype and leads to worse clinical outcomes [23-25]. Our study suggests that age by itself might not represent a specific factor for the acquisition of $P$. aeruginosa and we can speculate that exposure to different infections may be the result of different lifestyles and/or comorbidity. Furthermore, chronic infection with $P$. aeruginosa was not a predictor of 3-year mortality in our cohort. We could speculate that predisposing factors of vulnerability towards potential stressors (i.e., the reduced biological reserve occurring with age) are as important, if not more, than the precipitating factors (i.e., the bacterial virulence). It seems reasonable to think that it is the interaction between $P$. aeruginosa and the host, more than the sole presence of the pathogen that might affect a patient's biological reserve. The biological reserve is the final result of the number, type, severity and interaction of different diseases. Chronic infection with $P$. aeruginosa might accelerate the decline of each individual's biological reserve, leading to a poor quality of life and worse outcomes. This represents a crucial field for future research that should be focused on: a) the understanding of specific risk factors for acquiring chronic infection with $P$. aeruginosa, b) the evaluation of mechanisms of interaction between $P$. aeruginosa and the bronchiectatic host; c) the identification of biomarkers expressing this interaction; d) and, finally, the development of therapeutic strategies to interrupt the vicious cycle of $P$. aeruginosa decreasing patient's biological reserve to the point of death.

Results of our study might have other important implications. From a research perspective, a complete analysis of the number, type, severity and interaction of various diseases in bronchiectasis is urgently needed. From a clinical perspective, our results clearly indicate the need for pulmonologists taking care of patients with bronchiectasis to acquire specific geriatric competencies or, at least, create the premises for collaborating with physician experts in ageing and long-term care [14]. Among these competencies, the acquisition of geriatric methods to assess a patient's comorbidity and frailty should be a priority [26]. Furthermore, a special attention should be given to possible interactions between bronchiectasis therapies, such as long-term azithromycin, and other drugs elderly patients usually take for other diseases.

One of the limitations of this study is the inclusion of patients coming from tertiary care centers and the presence of missing data on 2- and 3-year mortality for $17 \%$ of our patients. Thus, the prevalence of older adults and elderly people with bronchiectasis might be underestimated if there is referral bias favoring younger adults. Another important limitation is the absence of data on causes of death that could help to differentiate between those patients who died "with" bronchiectasis and those who died "because of" bronchiectasis. This difference between bronchiectasis-related versus all-cause mortality is crucial especially in elderly patients and should be collected in future studies focused on this topic. Furthermore, patients' frailty and functional status would be important to understand the relationship between age and mortality in this patient population. Finally, we did not evaluate the potential interactions between bronchiectasis and specific diseases which may unveil clusters of comorbidity playing a relevant role in determining poor quality of life and increased mortality.

This is the largest cohort of outpatients with bronchiectasis published in the literature so far incorporating patients from six European countries. Furthermore, patients' enrolment is equally balanced among different centers.

\section{Conclusions}

This large European study confirms that among patients with bronchiectasis more than $50 \%$ are elderly and very elderly. In light of the absence of substantial differences in terms of bronchiectasis characteristics across age groups, other factors, possibly related to individual's frailty and vulnerability, might explain the increased rate of mortality we found in older patients. We strongly suggest that future research should be focused on individual's determinants of frailty with the aim to assess possible interactions with bronchiectasis and potential relationship with the outcomes.

\section{Conflict of interest}

No conflicts exist for all the authors.

\section{Funding information}

None.

\section{Acknowledgements}

This study was supported by the European Multicentre Bronchiectasis Audit and Research Collaboration (EMBARC; www. bronchiectasis.eu). EMBARC is an European Respiratory Society Clinical Research Collaboration and has received funding from the European Respiratory Society, Bayer HealthCare and Aradigm Corporation. James D Chalmers acknowledges fellowship support from the Medical Research Council and the Wellcome Trust. Melissa J McDonnell acknowledges fellowship support from the European Respiratory Society/European Lung Foundation and Health Research Board, Ireland.

Stefano Aliberti takes responsibility for the content of the manuscript, including the data and analysis. Study concept and design: GB, SA. Acquisition of data: JDC, MJM, PCG, KD, DS, AL, FP, DO. Analysis and interpretation of data: GB, SA, JDC, GS, SD. Drafting of the manuscript: GB, SA, GS, SD. Critical revision of the manuscript for important intellectual content: All authors. Statistical analysis: GS, SD. Study supervision: SA, JDC. All authors read and approved the final manuscript. No financial support has been given for this manuscript.

\section{Appendix A. Supplementary data}

Supplementary data related to this article can be found at http:// dx.doi.org/10.1016/j.rmed.2016.08.008.

\section{References}

[1] J.D. Chalmers, S. Aliberti, F. Blasi, Management of bronchiectasis in adults, Eur. Respir. J. 45 (5) (2015) 1446-1462. 
[2] J.K. Quint, E.R. Millett, M. Joshi, V. Navaratnam, S.L. Thomas, J.R. Hurst, et al. Changes in the incidence, prevalence and mortality of bronchiectasis in the UK from 2004 to 2013: a population-based cohort study, Eur. Respir. J. 47 (1) (2016) 186-193.

[3] A.E. Seitz, K.N. Olivier, C.A. Steiner, R. Montes de Oca, S.M. Holland, D.R. Prevots, Trends and burden of bronchiectasis associated hospitalizations in the United States, 1993-2006, Chest 138 (4) (2010) 944-949.

[4] H.J. Roberts, R. Hubbard, Trends in bronchiectasis mortality in England and Wales, Respir. Med. 104 (7) (2010) 981-985.

[5] R.L. Kane, R. Priester, A.M. Totten, Meeting the Challenge of Chronic Illness, The Johns Hopkins University Press, Baltimore, 2005, pp. 3-42.

[6] J.D. Chalmers, S. Aliberti, E. Polverino, M. Vendrell, M. Crichton, M. Loebinger, et al., The EMBARC European Bronchiectasis Registry: protocol for an international observational study, ERJ Open Res. 1 (2015) 00081-02015.

[7] M.C. Pasteur, D. Bilton, A.T. Hill, British Thoracic Society guideline for non-CF bronchiectasis, Thorax 65 (Suppl.1) (2010) i1-i58.

[8] M.E. Charlson, P. Pompei, K.L. Ales, C.R. MacKenzie, A new method of classifying prognostic comorbidity in longitudinal studies: development and validation, J. Chronic Dis. 40 (1987) 373-383.

[9] Global Initiative for Chronic Obstructive Lung Disease. Global Strategy for the Diagnosis, Management and Prevention of COPD. http://www.goldcopd.org/ uploads/users/files/GOLD_Report_2014_Jun11.pdf.

[10] J.D. Chalmers, P. Goeminne, S. Aliberti, M.J. McDonnell, S. Lonni, J. Davidson, et al., The bronchiectasis severity index. An international derivation and validation study, Am. J. Respir. Crit. Care Med. 189 (5) (2014) 576-585.

[11] C.B. Wilson, P.W. Jones, C.J. O'Leary, P.J. Cole, R. Wilson, Validation of the St. George's respiratory Questionnaire in bronchiectasis, Am. J. Respir. Crit. Care Med. 156 (1997) 536-541.

[12] M.C. Pasteur, S.M. Helliwell, S.J. Houghton, S.C. Webb, J.E. Foweraker R.A. Coulden, et al., An investigation into causative factors in patients with bronchiectasis, Am. J. Respir. Crit. Care Med. 162 (2000) 1277-1284.

[13] F.C. Ringshausen, A. de Roux, R. Diel, D. Hohmann, T. Welte, J. Rademacher, Bronchiectasis in Germany: a population-based estimation of disease prevalence, Eur. Respir. J. 46 (6) (2015) 1805-1807.

[14] G. Bellelli, S. Aliberti, Is it time for a "pneumo-geriatrician" for frail old patients with respiratory diseases? Eur. J. Intern Med. 25 (4) (2014) 303.

[15] G. Anderson, Chronic Care: Making the Case for Ongoing Care, Robert Wood Johnson Foundation, Princeton, NJ, 2010.
[16] J. Sundh, G. Johansson, K. Larsson, A. Lindén, C.G. Löfdahl, C. Janson, et al., Comorbidity and health-related quality of life in patients with severe chronic obstructive pulmonary disease attending Swedish secondary care units, Int. J. Chron. Obstruct Pulmon Dis. 10 (2015) 173-183.

[17] P.C. Goeminne, T.S. Nawrot, D. Ruttens, S. Seys, L.J. Dupont, Mortality in noncystic fibrosis bronchiectasis: a prospective cohort analysis, Respir. Med. 108 (2) (2014) 287-296.

[18] M.R. Loebinger, A.U. Wells, D.M. Hansell, N. Chinyanganya, A. Devaraj, M. Meister, et al., Mortality in bronchiectasis: a long-term study assessing the factors influencing survival, Eur. Respir. J. 34 (4) (2009 Oct) 843-849.

[19] A. Clegg, J. Young, S. Iliffe, M.O. Rikkert, K. Rockwood, Frailty in elderly people, Lancet 381 (9868) (2013) 752-762.

[20] L.P. Fried, C.M. Tangen, J. Walston, A.B. Newman, C. Hirsch, J. Gottdiener, et al. Frailty in older adults: evidence for a phenotype, J. Gerontol. A Biol. Sci. Med. Sci. 56 (3) (2001) M146-M156.

[21] K. Rockwood, K. Stadnyk, C. MacKnight, I. McDowell, R. Hébert, D.B. Hogan, A brief clinical instrument to classify frailty in elderly people, Lancet 353 (9148) (1999) 205-206.

[22] B.M. Buurman, J.G. Hoogerduijn, R.J. de Haan, A. Abu-Hanna, A.M. Lagaay, H.J. Verhaar, et al., Geriatric conditions in acutely hospitalized older patients: prevalence and one-year survival and functional decline, PLoS One 6 (11) (2011) e26951.

[23] S. Aliberti, S. Lonni, S. Dore, M.J. McDonnell, P.C. Goeminne, K. Dimakou, T.C. Fardon, R. Rutherford, A. Pesci, M.I. Restrepo, G. Sotgiu, J.D. Chalmers, Clinical phenotypes in adult patients with bronchiectasis, Eur. Respir. J. 47 (4) (2016 Apr) 1113-1122, http://dx.doi.org/10.1183/13993003.01899-2015.

[24] S. Finch, M.J. McDonnell, H. Abo-Leyah, S. Aliberti, J.D. Chalmers, A comprehensive analysis of the impact of Pseudomonas aeruginosa colonization on prognosis in adult bronchiectasis, Ann. Am. Thorac. Soc. 12 (11) (2015) 1602-1611.

[25] M.J. McDonnell, H.R. Jary, A. Perry, J.G. MacFarlane, K.L. Hester, T. Small, et al., Non cystic fibrosis bronchiectasis: a longitudinal retrospective observational cohort study of Pseudomonas persistence and resistance, Respir. Med. 109 (6) (2015) 716-726.

[26] V.M. Arora, M. Johnson, J. Olson, P.M. Podrazik, S. Levine, C.E. Dubeau, et al., Using assessing care of vulnerable elders quality indicators to measure quality of hospital care for vulnerable elders, J. Am. Geriatr. Soc. 55 (11) (2007) 1705-1711. 